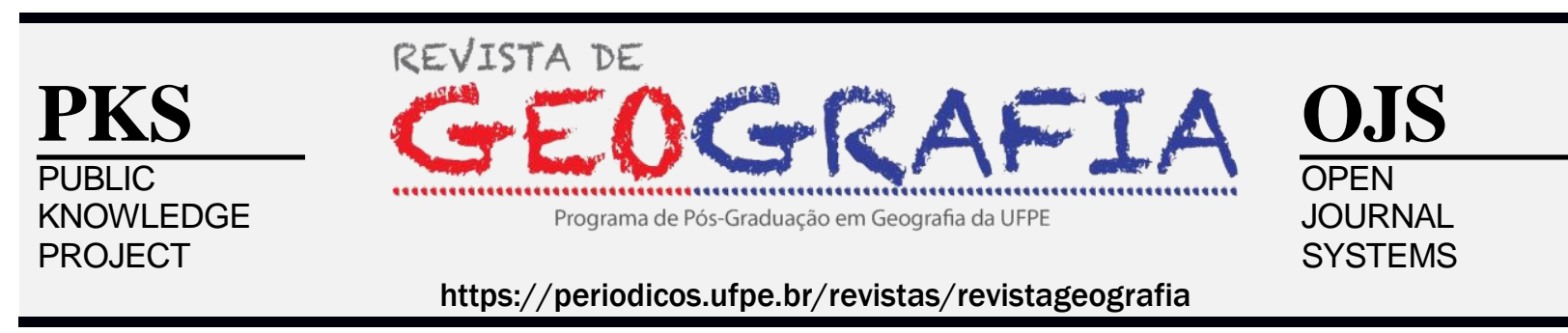

\title{
PESCA ARTESANAL DO MARISCO NO LITORAL PARAIBANO: RELAÇÕES SOCIOAMBIENTAIS E TECNOLOGIAS SOCIAIS
}

\author{
Ivo Raposo Gonçalves Cidreira-Neto ${ }^{1}$, Marília Lacerda Barbosa Fragoso ${ }^{2}$, Gilberto \\ Gonçalves Rodrigues ${ }^{3}$
}

\begin{abstract}
${ }^{1}$ Doutorando em Desenvolvimento e Meio Ambiente. Universidade Federal de Pernambuco. E-mail: ivo.raposo@hotmail.com

${ }^{2}$ Mestranda em Desenvolvimento e Meio Ambiente. Universidade Federal de Pernambuco. E-mail: marilialbf@gmail.com

${ }^{3}$ Professor do Departamento de Zoologia. Universidade Federal de Pernambuco. E-mail: gilbertorodrigues.ufpe@gmail.com
\end{abstract}

Artigo recebido em 04/04/18 e aceito em 06/12/18

\begin{abstract}
RESUMO
A pesca artesanal é uma atividade baseada na produção em pequena escala realizada a partir de diversas formas de interações socioambientais. Dessa forma, o objetivo deste trabalho foi descrever as técnicas e estratégias socioambientais desenvolvidas em três comunidades da região costeira do Estado da Paraíba. Para tal, foi utilizada a observação direta e participante durante os anos de 2016 a 2018. A arte de pesca apresenta padrões geométricos de acordo com a distância formada nos momentos de catação e singularidades como as formas de manejo e beneficiamento. As tecnologias sociais desenvolvidas fazem parte da própria construção identitária do pescador artesanal, que por diversas vezes relaciona o trabalho com seu bem-estar.
\end{abstract}

Palavras-chave: Mariscagem; sítios de pertencimento; territorialidade.

\section{ARTISANAL FISHING OF SHELLFISH IN THE PARAÍBA COAST: SOCIO-ENVIRONMENTAL RELATIONS AND SOCIAL TECHNOLOGIES}

\begin{abstract}
Artisanal fishing is an activity based on small-scale production executed from various forms of socioenvironmental interactions. Thus, the objective of this work is to describe the socioenvironmental techniques and strategies developed in three community's localizeted in the coastal region of Paraíba State. For this, direct and participant observation was used during the years 2016 to 2018. The art of fishing presents geometric patterns according to the distance formed in the moments of harvest and singularities as the forms of handling and processing. The developed social technologies are part of the own identity construction of the artisanal fisherman, that in several times relates the work with its well-being.
\end{abstract}

Keywords: Shellfishing; local of belonging; territoriality. 


\section{INTRODUÇÃO}

O Brasil é o quinto país com maior área costeira $\left(8.516 .000 \mathrm{~km}^{2}\right)$, contendo uma diversidade de ecossistemas / biomas (TESSLER e GOYA, 2005; NEVES e MUEBE, 2008) e culturas associadas a estes ambientes (ELOY et al., 2014). Dentre eles, os manguezais representam relevante importância socioambiental devido às diversas comunidades tradicionais que vivem principalmente da pesca de peixes, crustáceos e moluscos encontrados nesses ecossistemas (ALVES e NISHIDA, 2002; NISHIDA, NORDI e ALVES, 2004; ELOY et al., 2014).

A pesca brasileira pode ser classificada em três principais ramificações, sendo: (i) Subsistência, fundamentada na economia da troca; (ii) Pequena Produção, que pode ser subdivida entre pescadores lavradores e pescadores artesanais, e (iii) Empresarial, com base econômica capitalista (DIEGUES, 1995). Dessa forma, a pesca artesanal representa mais do que uma relação de compra/venda ou trabalho/lazer, resultando em construções socioambientais que permeiam diversos capilares da relação sociedade-natureza (DIEGUES, 2000; RAMALHO, 2015).

Segundo Diegues (2001), os modos de vida que os pequenos produtores desenvolveram são dependentes de ciclos naturais, e envolvem conhecimentos acerca dos ciclos biológicos e recursos naturais disponíveis na região em que se encontram. Os pescadores e pescadoras conhecem e fazem parte da conexão existente entre o rio, o mar e a terra, sendo dotados de conhecimento adquirido através da repetição de sua atividade nesses ambientes, tornando-se parte dessa complexa relação (SILVEIRA et al., 2013).

A mariscagem é uma atividade artesanal, que consiste na catação de moluscos bivalves (OLIVEIRA e EL-DEIR, 2013) na qual a Anomalocardia flexuosa (LINNAEUS, 1767) possui a maior representatividade econômica, conhecido popularmente como marisco (SOUTO e MARTINS, 2009) e/ou marisco-pedra (CIDREIRA-NETO et al., 2018). Os pescadores e pescadoras que trabalham com a catação do marisco têm essa atividade como principal fonte de renda (JESUS e PROST, 2011), que é influenciada diretamente pela quantidade de dias trabalhados e pela sazonalidade.

A catação é realizada nos bancos de areia (croas) que ficam visíveis durante a maré baixa, durante todo o ano, apresentando variação na quantidade de marisco em diferentes estações do ano (período chuvoso e seco). Devido à estreita relação com as áreas de catação ao longo do tempo, as marisqueiras apresentam amplo conhecimento acerca de fatores ambientais que influenciam no seu trabalho, como variação da maré, correntes aquáticas, 
temperatura e salinidade, assim como condições biológicas e ecológicas dos mariscos (NISHIDA, NORDI e ALVES, 2004; SOUTO e MARTINS, 2009).

A mariscagem apresenta uma relação econômica de baixa escala, diferente do encontrado nas relações socioeconômicas capitalistas, baseada no acúmulo de capital. Essa atividade pode ser caracterizada como tradicional/artesanal realizada em núcleos familiares e sociais, desenvolvidos horizontalmente, passados principalmente através da oralidade e sua prática diária. Bezerril (2012, p.6) comenta que:

Para aqueles que não estão envolvidos com a pesca, mariscar pode parecer, à primeira vista, uma prática sem maiores elaborações, mas sob um olhar atento, a atividade se constitui como um campo de complexas relações, saberes, significados e interesses que vêm sendo construídos ao longo da história e são afirmados na memória de um grupo de mulheres.

A relação sociedade-natureza não é algo de simples explicação, apresentando diferentes configurações ao longo da evolução das sociedades e dos diferentes sistemas econômicos, principalmente devido à organização dos espaços geográficos (CIDREIRANETO e RODRIGUES, 2017). O “ser tradicional” implica em diferentes construções sociais e ambientais, apresentando de forma mais orgânica entre as diferentes configurações do espaço ocupado.

Os sítios simbólicos de pertencimento são construções imateriais que agregam diversas interfaces das relações sociais, como construção de valores, atividades perpassadas entre gerações, ultrapassando as escalas de tempo (ZAOUAL, 2006). Esses espaços fazem parte da práxis dos pescadores, onde desenvolvem suas relações e se sentem parte do local.

Rodrigues et al. (2017) traz que para comunidades pesqueiras tracionais o território ultrapassa fronteiras físicas, apresentando diferentes conceitos de território, territorialidade e espaço. Santos (2006, p.39) compreende espaço como "um conjunto indissociável, solidário e contraditório, de sistemas de objetos e sistemas de ações, não considerados isoladamente, mas como o quadro único no qual a história se dá". Os espaços utilizados tanto para fins da atividade pesqueira, quanto para o desenvolvimento das relações sociais, compõem o território pesqueiro, agregando as formas de relações socioambientais provenientes da pesca. O reconhecimento desses locais se dá a partir de conceitos históricos, culturais e de identidade (JENTOFT, MCCAY e WILSON, 1998), assim como dos mecanismos/relações sociais que envolvem toda a atividade.

Tecnologias sociais podem ser caracterizadas como um conjunto de técnicas utilizadas levando em consideração a realidade local, sendo reconhecidas pela comunidade e 
passadas através de gerações (LASSANCE-JR e PEDREIRA, 2004; MACIEL e FERNANDES, 2011). Dessa forma, as tecnologias sociais auxiliam o próprio reconhecimento do pescador na comunidade pesqueira, visto que eles se reconhecem (também) pelos padrões e formas (arte) de pesca. Nascimento (2015) traz que o território pesqueiro não apresenta cerca para demarcação, sendo os elementos sociais/ambientais que ditam quem é "de fora" ou "de dentro".

O objetivo geral foi descrever as relações socioambientais da pesca artesanal do marisco no litoral paraibano, enfatizando o uso das tecnologias sociais nas comunidades estudadas.

\section{MATERIAL E MÉTODOS}

A metodologia foi construída com base em visitas em três comunidades pesqueiras do Estado da Paraíba, sendo: (i) Aldeia de Tramataia, situada na Área de Proteção Ambiental Barra do Rio Mamanguape, litoral Norte; (ii) Porto da Oficina, no município de Bayeux, região metropolitana próxima a capital João Pessoa e (iii) Acaú, situada na Reserva Extrativista Acaú-Goiana, litoral Sul (Figura 1 e 2). As visitas foram realizadas durante 2016 a 2018, totalizando três visitas em cada comunidade, com o objetivo de participar das atividades pesqueiras da região e criar laços com as marisqueiras.
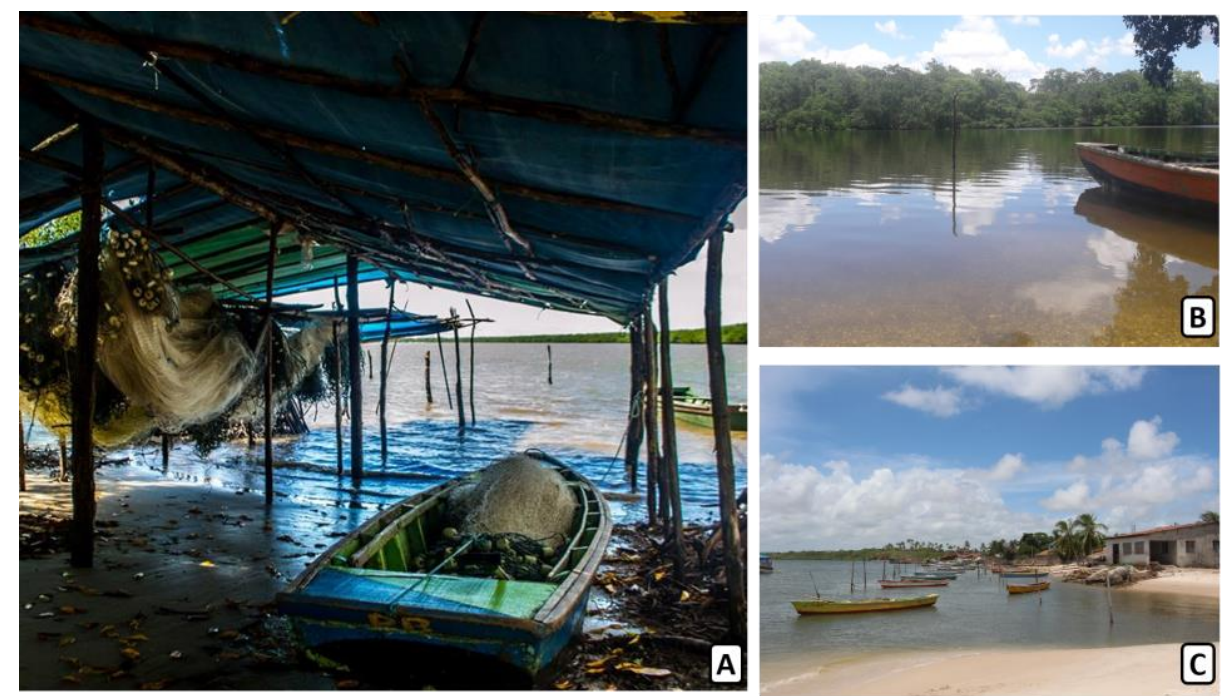

Figura 1. Portos de embarque. A. Aldeia de Tramataia. B. Bayeux. C. Acaú.

Fonte: Ivo Cidreira-Neto. 


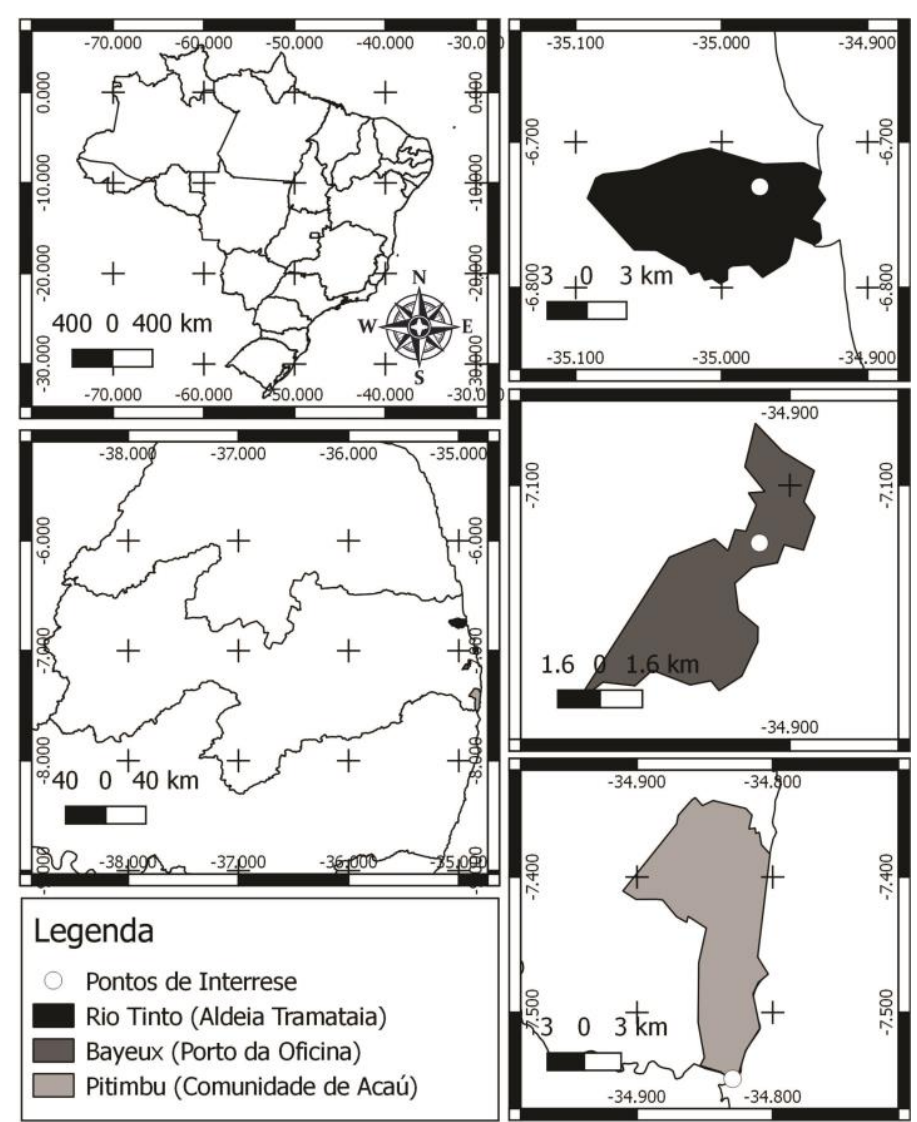

Figura 2. Localização das comunidades estudadas.

Fonte: Autores, 2018.

As técnicas utilizadas foram de observação direta (ou simples) e observação participante, a primeira corresponde a uma maneira espontânea de analisar um determinado fator social, no qual pesquisador permanece a parte da atividade, sendo caracterizado como um mero espectador. A segunda técnica consiste na participação ativa do pesquisador dentro do grupo social, assumindo por hora o posto de membro (GIL, 2002; 2008), atuando em conjunto com o pescador na atividade de pesca e nos processos subseqüentes de transporte para preparação do produto para o consumo e/ou comercialização.

A utilização compartilhada destas técnicas metodológicas de observação possibilita uma descrição das tecnologias sociais desenvolvidas pelos pescadores na catação do marisco, assim como permite ao pesquisador vivenciar a atividade no seu próprio contexto.

\section{RELAÇÕES SOCIOAMBIENTAIS E TECNOLOGIAS SOCIAIS}

Pesca artesanal é uma atividade guiada pela dinâmica da maré, onde as transições entre alta e baixa constroem as interações socioambientais proporcionadas nessa categoria. $\mathrm{Na}$ 
mariscagem não é diferente, as mulheres marisqueiras e homens marisqueiros conhecem bem o fluxo da maré, sendo este o seu único patrão, ditando os horários, dias e períodos de pesca. Ramalho (2015) traz que por diversas vezes o tempo livre e o tempo de trabalho se confundem, transformando-os em algo não antagônico. O pescador apresenta conhecimento baseado nas experiências de vida, assim como passados através da oralidade, formando e se reconhecendo como pescador, onde o afetivo move as relações sociais, contrário ao proposto pelo sistema capitalista (RAMALHO, 2011).

A mariscagem se inicia no período de baixa maré, que possibilita o aparecimento dos bancos de areia (croas), local onde será realizada a catação. Sozinhas ou em pequenos grupos formados por familiares e/ou amigos, as marisqueiras começam a surgir, carregando galeias, baldes e cestas, que servirão para o acondicionamento do produto pescado no dia (Figura 3). Aos poucos vão se espalhando, de forma quase geométrica, procurando os melhores locais, criando configurações dinâmicas e vivas, modificados de maneira quase natural.

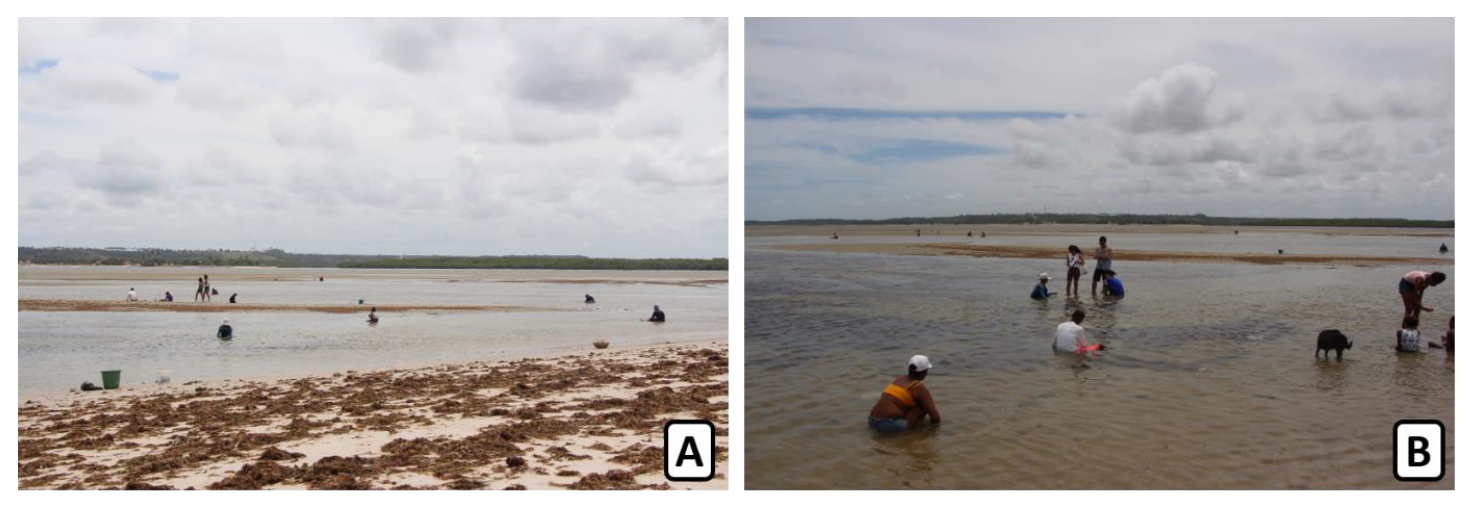

Figura 3. A e B - Marisqueiras realizando a catação nos bancos de areia (croas) na comunidade de Acaú, situada no litoral Sul da Paraíba.

Fonte: Marília Fragoso, 2018.

A croa será escolhida com base em alguns fatores, como distâncias até a residência, necessidade de utilizar de embarcações, estação do ano e horário da maré, assim como através do conhecimento empírico acerca de quais são os locais que apresentam melhor quantidade/qualidade do marisco. Souto e Martins (2009) demonstram que as marisqueiras possuem conhecimento da biologia e ecologia do marisco, comentando acerca do seu hábito alimentar, relacionando o período seco/chuvoso e as fases da lua com a disponibilidade de marisco. Tudo isto confere ao chamado Conhecimento Ecológico Local (CEL), que na sua essência é o conjunto dos conhecimentos obtidos através da oralidade e prática. Dessa forma, Toledo e Barrera-Bassols (2009) comentam que a memória é o recurso mais importante nas 
comunidades tracionais, visto que é através dela que o conhecimento é transmitido para as seguintes gerações.

Após a escolha do local, se inicia a pesca propriamente dita, que nessa etapa pode ser desenvolvida manualmente ou com o auxílio de instrumentos (Figura 4) (OLIVEIRA, CASTILHO e EL-DEIR, 2016). A pesca manual é realizada através do revolvimento do sedimento com as mãos, na qual os mariscos são extraídos e acomodados nos baldes. As marisqueiras ficam curvadas ou sentadas nas croas, sendo expostas a quatro ou cinco horas de sol por dia, de acordo com a duração da maré, utilizando chapéus e camisas de manga comprida para se proteger.
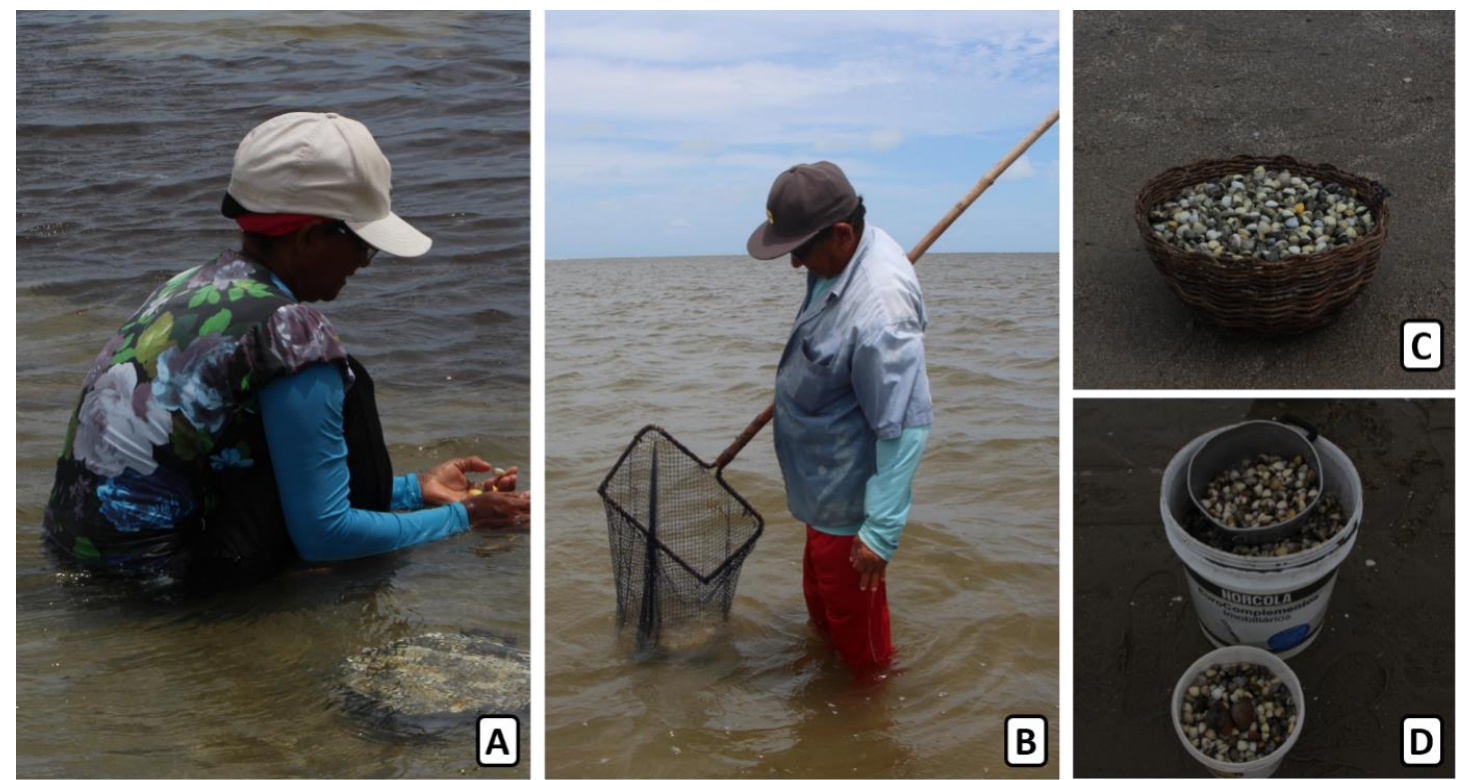

Figura 4. Diferentes tecnologias sociais da mariscagem. A. Marisqueira realizando a catação manual do marisco. B. Marisqueiro utilizando o puçá para a coleta do marisco. C. Cesto ou galéa utilizado para o condicionamento do marisco durante a pesca nas croas. D. Balde com os mariscos coletados manualmente durante um dia de trabalho.

Fonte: Marília Fragoso, 2017.

A catação manual permite a coleta apenas dos tamanhos maiores dos mariscos, rejeitando os pequenos, sem grandes danos a população da espécie. A separação é uma ação importante, visto que ela auxilia na manutenção das populações de marisco. Barreira e Araújo (2005) demonstram que a partir de um tamanho de aproximadamente $13 \mathrm{~mm}$ é que se tem o início da maturação sexual, possibilitando a reprodução e perpetuação da espécie.

A catação com instrumentos de coleta ocorre preferencialmente em locais ainda alagados, croas mais distantes da costa, que necessitam do auxílio de embarcação. Cada localidade apresenta um instrumento específico, fabricado manualmente, abrangendo a 
necessidade de cada indivíduo (Figura 5). Alguns deles são: (i) puçá (de cabo e de mão); (ii) gadanho e (iii) jereré, configurando-os como tecnologias sociais (TS). A presença destas TS possibilita o aumento na quantidade de mariscos coletados, chegando ao dobro da catação manual.

A técnica de utilização destas TS na catação pode causar danos aos mariscos pequenos durante a separação, pois é realizada através de batidas em caixotes com certo diâmetro no fundo que possibilitam que os mariscos de tamanhos inferiores passem por eles, segundo algumas marisqueiras (que realizam a catação manual), essas batidas necessárias para a separação do marisco podem danificar as cascas.

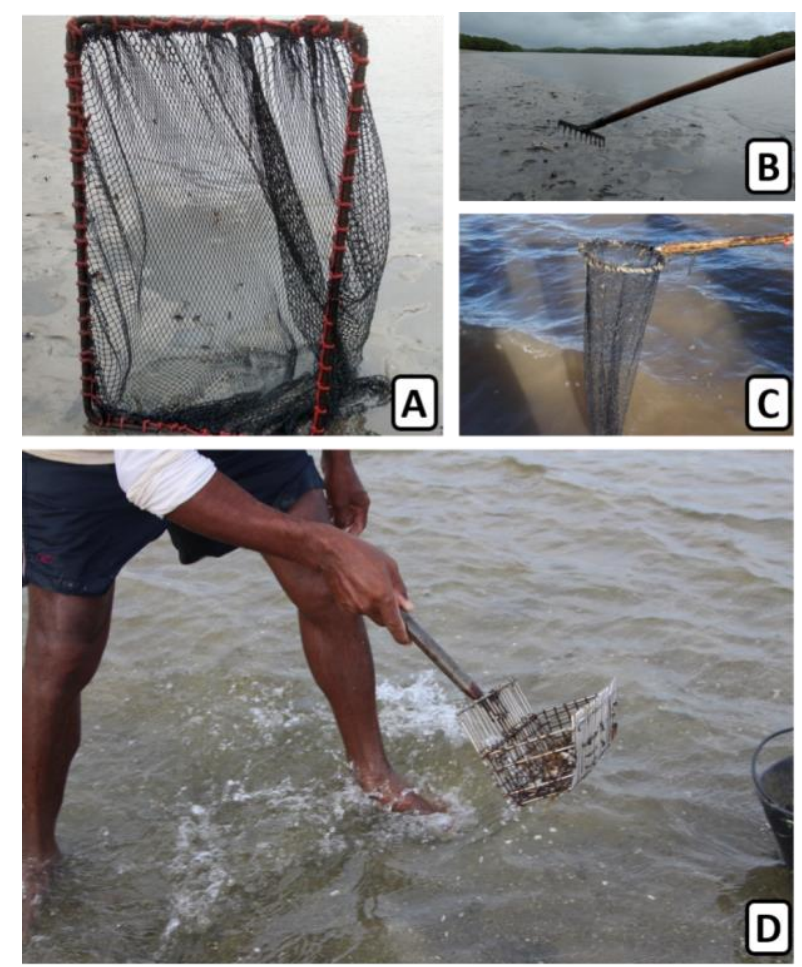

Figura 5. Tecnologias sociais com fabrico artesanal para realizar a pesca do marisco. A. Puçá de mão. B. Jererê. C. Puçá de cabo. D. Puçá.

Fonte: Autores, 2018.

A utilização de TS está relacionada diretamente com o fator econômico, visto que maiores quantidades de mariscos pescados irão resultar em maior renda. As dificuldades da pesca artesanal, como a carência de auxílios governamentais e políticas públicas eficazes, despertam o interesse pela utilização de mecanismos que proporcionem esse aumento na renda diária. Oliveira, Castilho e El-Deir (2016) trazem que a carência de investimento governamental surge como precursor dos conflitos socioambientais envolvidos na pesca 
artesanal, podendo resultar na descaracterização das atividades tradicionais e consequente rompimento da relação sociedade-natureza.

Ao final do processo de pesca, os mariscos acomodados nos baldes são levados para as residências das marisqueiras, local que será realizado o beneficiamento (Figura 6). Segundo elas, existem dois fatores negativos na coleta do marisco: o "carrego" e o “cozinhar". O primeiro em decorrência do peso dos baldes e sacos contendo os mariscos, e o segundo por causa do calor liberado pela lenha dos fogões durante o cozimento. Pena, Martins e Rêgo (2013) comentam acerca dos problemas de saúde das pescadoras decorrentes aos movimentos repetitivos e ao elevado esforço físico devido ao peso dos mariscos.

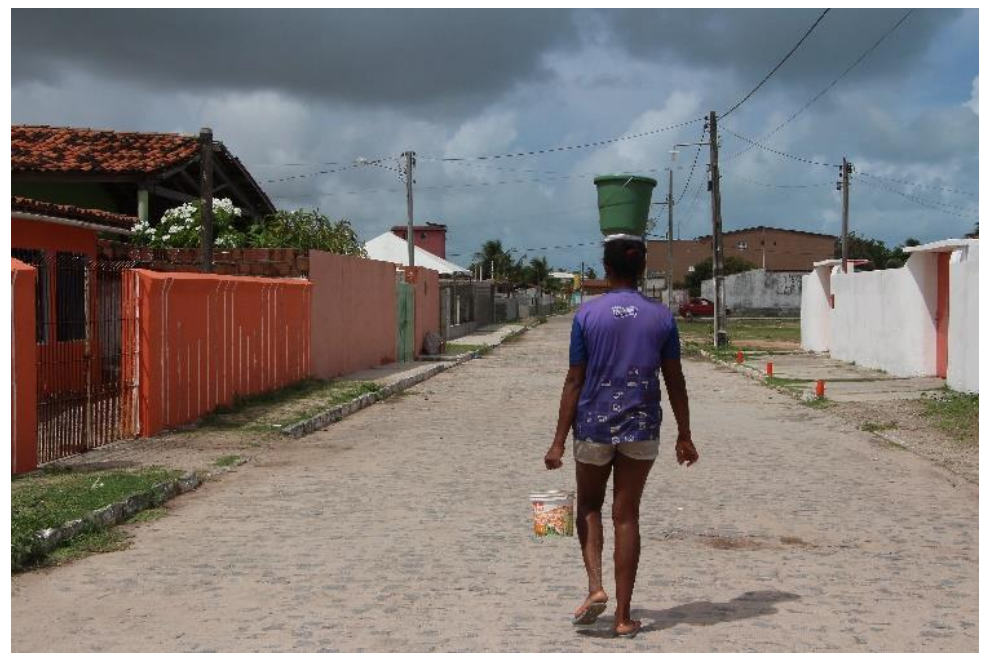

Figura 6. Marisqueira carregando os mariscos pescado para casa.

Fonte: Marília Fragoso, 2018.

Por fim, tem-se o beneficiamento do marisco que consiste na retirada da carne, composto por quatro principais etapas sendo: (i) cozimento, (ii) retirada da carne, (iii) lavagem da carne, (iv) pesagem/embalo para comercialização. O marisco coletado geralmente é beneficiado no dia seguinte à coleta, pois dessa forma a carne fica mais consistente, não desmanchando com facilidade. Dias, Rosa e Damasceno (2007) relatam que a lenha utilizada no cozimento é proveniente dos manguezais adjacentes e a busca por este material se dá no momento da chegada com o marisco.

A forma de debulhar o marisco (retirar a carne no processo de beneficiamento) influência no valor final do produto. Existem duas formas principais para beneficiar o marisco, sendo uma com o auxílio de uma peneira artesanal (Figura 7A), fabricada com engradados, no qual após o procedimento de cozimento o marisco é "batido" para que a carne 
solte das conchas e caia em outro recipiente. A outra forma é a retirada manual da carne (Figura 7B).
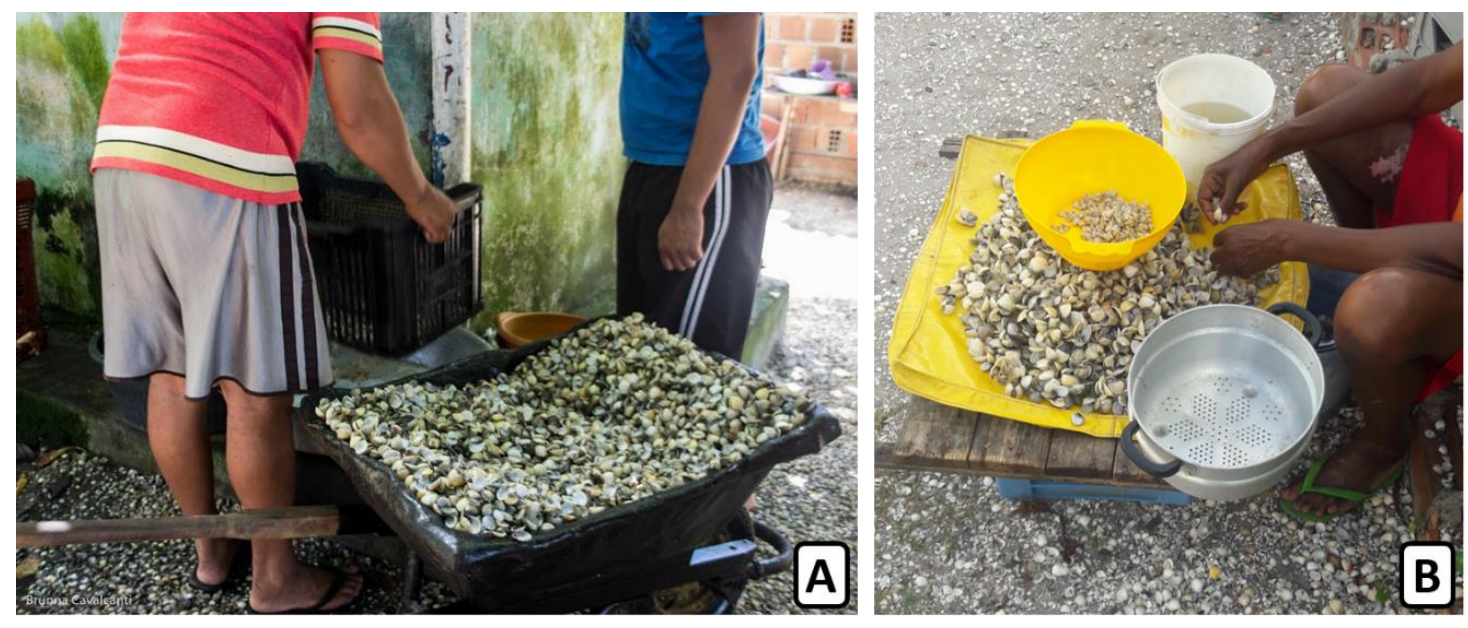

Figura 7. Formas de debulhar o marisco. A. Utilização da peneira artesanal para realizar a separa entra a cerne e as cascas do marisco. B. Separação manual.

Fonte: Autores, 2018.

A utilização da peneira resulta em um produto de qualidade inferior do marisco, devido à presença de partes da casca que quebram durante o processo, chegando a ser vendido por quase metade do valor do marisco beneficiado manualmente. $\mathrm{O}$ tempo necessário para o beneficiamento manual é maior do que quando realizado com a peneira, porém a carne do marisco resultante deste processo apresenta uma excelente qualidade que determina a maior valoração do produto.

Outros fatores também influenciam no valor da carne do marisco, como a disponibilidade nas croas, que segundo as marisqueiras, pode variar de acordo com as estações seca e a chuvosa, e a alta temporada no verão, com a chegada de veranistas nas praias que resulta no aumento da procura por mariscos e consequentemente do seu valor.

O conhecimento das marisqueiras sobre as técnicas de coleta do marisco é transmitido de geração para geração. Geralmente as mães repassam esse conhecimento oralmente ou através da experimentação, principalmente quando elas levam suas filhas para acompanharem ou ajudarem na coleta dos mariscos (prática comum). Nessa situação, o aprendizado acontece também por meio da observação da atividade de coleta. Dessa forma, a atividade de mariscagem começa desde a infância e pode se tornar a única fonte de sustento para esses pescadores durante toda a vida. 


\section{CONSIDERAÇÕES FINAIS}

A pesca artesanal engloba diversas etapas, as de pré-pesca, nas quais são tomadas as decisões de qual o local será escolhido, assim como a chegada propriamente dita no local. Seguida pela pesca, na qual o pescador desenvolve a sua atividade, e por fim tem-se a póspesca, compreendendo os processos de beneficiamento e destinação final do produto.

As interações socioambientais estão presentes em todas as etapas, o que explica o fato de que as relações de trabalho por vezes se intercruzam com o lazer, tornando a atividade prazerosa (bem-estar), diferente das formas tradicionais capitalistas de emprego.

Por fim, tem-se que as tecnologias sociais utilizadas por comunidades pesqueiras ao longo do litoral da Paraíba fazem parte da própria construção do indivíduo enquanto ser pescador(a), e nessa construção, o mesmo vê a sua arte de pesca como um conjunto de fatores, como os instrumentos pesqueiros, laços sociais e relação com o meio ambiente.

\section{REFERÊNCIAS}

ALVES, Rômulo Romeu da Nóbrega; NISHIDA, Alberto Kioharu. A ecdise do caranguejouçá, Ucides cordatus L. (DECADOPA, BRACHYURA) na visão dos caranguejeiros. Interciência, v.27, n.3, p.110-117, 2002.

BEZERRIL, Gustava. Trabalho no mangue: os saberes e a busca por valorização das marisqueiras de Fortim - Ceará. Cadernos do LEME, Campina Grande, v.4, n.1, p.5-33, 2012.

CIDREIRA-NETO, Ivo Raposo Gonçalves; RODRIGUES, Gilberto Gonçalves. Relação homem-natureza e os limites para o desenvolvimento sustentável. Revista de Movimentos Sociais e Dinâmicas Espaciais, Recife, v.6, n.2, p.142-156, 2017.

CIDREIRA-NETO, Ivo Raposo Gonçalves; NASCIMENTO, Douglas Macêdo; MORAES, Priscila Xavier de; RODRIGUES, Gilberto Gonçalves. Análise biométrica de Anomalocardia flexuosa em Área de Proteção Ambiental. Journal of Environmental Analysis and Progress, Recife, v.1, n.2, p.181-189, 2018.

DIEGUES, Antônio Carlos Santana. Povos e mares: leituras em sócio-antropologia marítima. São Paulo: NUPAUB-USP, 1995.

DIEGUES, Antônio Carlos Santana (Org.). Os saberes tradicionais e a biodiversidade no Brasil. São Paulo: MMA-COBIO-NUPAUB, 2000. 
DIEGUES, Antônio Carlos Santana. O mito moderno da natureza intocada. $3^{\text {a }}$ ed. São Paulo: Hucitec, 2001.

DIAS, Thelma Lúcia Pereira; ROSA, Ricardo de Souza; DAMASCENO, Luís Carlos Pereira. Aspectos socioeconômico, percepção ambiental e perspectivas das mulheres marisqueiras da Reserva de Desenvolvimento Sustentável Ponta do Tubarão (Rio Grande do Norte, Brasil). Gaia Scientia, v.1, n.1, p.25-35, 2007.

ELOY, Christinne Costa; VIEIRA, Danielle Machado; LUCENA, Camilla Marques de; ANDRADE, Maristela Oliveira de. Apropriação e proteção dos conhecimentos tradicionais no Brasil: a conservação da biodiversidade e os direitos das populações tradicionais. Gaia Scientia, Paraíba, v.8, n.2, p.189-198, 2014.

GIL, Antônio Carlos. Como elaborar projetos de pesquisa. $4^{\text {a }}$ ed. São Paulo: Atlas, 2002.

GIL, Antônio Carlos. Métodos e técnicas de pesquisa social. $6^{\text {a }}$ ed. São Paulo: Atlas, 2008. JENTOFT, Svein. MCCAY, Bonnie; WILSON, Douglas. Social theory and fisheries comanagement. Marine policy, v.22, n.4-5, p.423-436, 1998.

JESUS, Rosenaide Santos; PROST, Catherine. Importância da atividade artesanal de mariscagem para as populações nos municípios de Madre de Deus e Saubara, Bahia. GEOUSP - Espaço e Tempo, São Paulo, n.30, p.123-137, 2011.

LASSANCE-JR, Antônio; PEDREIRA, Juçara Santiago. Tecnologias sociais e políticas públicas. In: PAULO, Antônio de; MELLO, Claiton José; NASCIMENTO-FILHO, Lenart; KORACAKIS, Teodoro (Orgs.). Tecnologia social: uma estratégia para o desenvolvimento. Rio de Janeiro: Fundação Banco do Brasil, 2004, p.65-81.

MACIEL, Ana Lúcia Suárez; FERNANDES, Rosa Maria Castilhos. Tecnologias sociais: interface com as políticas públicas e o serviço social. Serviço Social \& Sociedade, São Paulo, n.106, p.146-165, 2011.

NEVES, Claudio Freitas; NUEBE, Dieter. Vulnerabilidade, impactos e adaptação a mudanças do clima: a zona costeira. Parcerias Estratégicas, Brasília, v.13, n.27, p.217-296, 2010.

NISHIDA, Alberto Kioharu; NORDI, Nivaldo; ALVES, Rômulo Romeu da Nóbrega. Abordagem etnoecológica da coleta de moluscos no litoral paraibano. Tropical Oceanography, Recife, v.32, n.1, p.53-68, 2004.

OLIVEIRA, Bruno Marcel Carneval de; EL-DEIR, Soraya Giovanetti. Mariscagem: um desafio para o litoral norte de Pernambuco. Recife: Edufrpe, 2013. 
OLIVEIRA, Bruno Marcel Carneval de; CASTILHO, Cláudio Jorge de Moura; EL-DEIR, Soraya Giovanetti. Por uma gestão ambiental integrada na mariscagem pernambucana. Revista de Movimentos Sociais e Dinâmicas Espaciais, Recife, v.5, n.1, p.160-183, 2016. PENA, Paulo Gilvane Lopes; MARTINS, Vera; REGO, Rita Franco. Por uma política para a saúde do trabalhador não assalariado: o caso dos pescadores artesanais e das marisqueiras. Revista Brasileira de Saúde Ocupacional, São Paulo, v.38, n.127, p.57-68, 2013.

RAMALHO, Cristiano Wellington Norberto. O sentir dos sentidos dos pescadores artesanais. Revista de Antropologia, São Paulo, v.54, n.1, p.315-352, 2011.

RAMALHO, Cristiano Wellington Norberto. A desnecessidade do trabalho entre pescadores artesanais. Sociologias, Porto Alegre, v.17, n.38, p.192-220, 2015.

RODRIGUES, Gilberto Gonçalves; SOUZA, Ana Elizabete Vila Nova de; LIMA, Maira Egito Alves; CIDREIRA-NETO, Ivo Raposo Gonçalves; LEITE, Jéssika Kellyane da Silva; NASCIMENTO, Douglas Macêdo; HARDER, Eduardo; FREITAS, Ana Elisa Castro e. Território, paisagens e identidades culturais em uma Reserva Extrativista Marinha do Nordeste do brasileiro. Revista de Movimentos Sociais e Dinâmicas Espaciais, Recife, v.6, n.1, p.235-343, 2017.

SANTOS, Milton. A natureza do espaço: técnica e tempo, razão e emoção. São Paulo: Editora da Universidade de São Paulo, 2006.

SILVEIRA, Pedro Castelo Branco; MESQUITA, Beatriz; MELO, Luciana; OLIVEIRAFILHO, Ivson. Estuário, paisagem-fluxo de pescadores artesanais. Iluminuras, Porto Alegre, v.14, n.34, p.304-323, 2013.

SOUTO, Francisco José Bezerra; MARTINS, Viviane Souza. Conhecimentos etnoecológicos na mariscagem de moluscos bivalves no manguezal do Distrito de Acupe, Santo Amaro - BA. Revista Biotemas, v.22, n.4, p.207-218, 2009.

TESSLER, Moysés Gonsalez; GOYA, Samara Cazzoli y. Processos Costeiros Condicionantes do Litoral Brasileiro. Revista do Departamento de Geografia, São Paulo, v.17, p.11-23, 2005.

TOLEDO, Victor Manuel; BARRERA-BASSOLS, Narciso. A etnoecologia: uma ciência pós-moderna que estuda as sabedorias tradicionais. Revista de Desenvolvimento e Meio Ambiente, n.20, p.31-45, 2009.

ZAOUAL, Hassan. Nova economia das iniciativas locais: uma introdução ao pensamento pós-global. Rio de Janeiro: DP\&A; COPPE/UFRJ, 2006. 